\title{
The $90^{\circ}$ rotation technique improves the ease of insertion of the ProSeal ${ }^{\mathrm{TM}}$ laryngeal mask airway in children La technique de rotation à $90^{\circ}$ améliore la facilité d'insertion du
masque laryngé ProSeal ${ }^{\mathrm{TM}}$ chez les enfants
}

\author{
Mi-Ja Yun, MD · Jung-Won Hwang, MD • Sang-Heon Park, MD • \\ Sung-Hee Han, MD · Hee-Pyoung Park, MD · Jin-Hee Kim, MD • \\ Young-Tae Jeon, MD $\cdot$ Sang-Chul Lee, MD
}

Received: 1 October 2010/Accepted: 20 December 2010/Published online: 4 January 2011

(C) Canadian Anesthesiologists' Society 2010

\begin{abstract}
Background A previous study using a $180^{\circ}$ rotation to insert the ProSeal ${ }^{T M}$ laryngeal mask airway (LMA ProSeal) in children did not show improvement over the standard technique. We used a $90^{\circ}$ rotation technique to insert the LMA ProSeal in pediatric patients and compared ease of insertion and pharyngeal trauma with the standard technique.

Methods This prospective randomized controlled study included 126 patients aged three to nine years. Anesthesia was induced with thiopental and rocuronium, and the LMA ProSeal used in the study ranged in size from 2 to 3 depending on the patient's body weight. In the control group $(n=63)$, the LMA ProSeal was inserted using the index finger. In the rotation group $(n=63)$, the entire cuff of the LMA ProSeal was placed in the patient's mouth without finger insertion and rotated $90^{\circ}$ counter clockwise around the tongue. The LMA ProSeal was then advanced and rotated back until resistance was felt. The primary outcome was the insertion success rate at first attempt.
\end{abstract}

\section{M.-J. Yun, MD}

Department of Anesthesiology and Pain Medicine, National Medical Center, Seoul, South Korea

J.-W. Hwang, MD ( $\bowtie) \cdot$ S.-H. Park, MD · S.-H. Han, MD . J.-H. Kim, MD · Y.-T. Jeon, MD

Department of Anesthesiology and Pain Medicine, Seoul National University Bundang Hospital, College of Medicine, Seoul National University, Seongnam, South Korea

e-mail: jungwon@snubh.org

H.-P. Park, MD - S.-C. Lee, MD

Department of Anesthesiology and Pain Medicine, Seoul National University Hospital, College of Medicine, Seoul National University, Seoul, South Korea
Results The success rate of insertion at first attempt was higher with the rotation technique than with the standard technique (97\% vs 70\%, respectively; $P<0.001)$ and the insertion time was shorter $(16 \pm 6 \mathrm{sec}$ vs $30 \pm 24 \mathrm{sec}$, respectively; $P<0.001$ ). Mean blood pressure after LMA ProSeal insertion increased significantly in the control group $(62 \pm 12$ to $69 \pm 17 \mathrm{mmHg} ; P=0.01)$, but not in the rotation group. The incidence of blood staining was lower in the rotation group than in the control group $(10 \%$ vs $25 \%$, respectively; $P=0.03$ ), but the incidence of sore throat was not significantly different $(24 \%$ vs $22 \%$, respectively; $P=0.9$ ).

Conclusions The $90^{\circ}$ rotation technique improves ease of insertion of the LMA ProSeal in children, and it decreases the risk of pharyngeal trauma. (ClinicalTrials.gov number, NCT01076725)

\section{Résumé}

Contexte Une étude précédente évaluant une technique de rotation à $180^{\circ}$ afin d'insérer le masque laryngé ProSeal $^{T M}$ (LMA ProSeal) chez des enfants n'a pas démontré d'amélioration par rapport à la technique standard. Nous avons utilisé une technique de rotation à $90^{\circ}$ afin d'insérer un LMA ProSeal chez des enfants et en avons comparé la facilité d'insertion et les lésions pharyngées par rapport à une technique standard.

Méthode Dans cette étude prospective, randomisée et contrôlée, on a recruté 126 patients âgés de trois à neuf ans. L'anesthésie a été induite avec du thiopental et du rocuronium, et les masques LMA ProSeal utilisés dans l'étude étaient de tailles 2 à 3 selon le poids du patient. Dans le groupe témoin $(n=63)$, le LMA ProSeal a été inséré à l'aide de l'index. Dans le groupe avec technique de rotation $(n=63)$, le ballonnet du LMA ProSeal a été 
placé dans la bouche du patient sans insertion du doigt, puis tourné de $90^{\circ}$ dans le sens inverse des aiguilles d'une montre autour de la langue. Le LMA ProSeal a ensuite été avancé puis retourné jusqu'à ce qu'on sente une résistance. Le critère d'évaluation principal était le taux de réussite à la première insertion.

Résultats Le taux de réussite de l'insertion à la première tentative était plus élevé avec la technique de rotation qu'avec la technique standard $(97 \%$ vs $70 \%$, respectivement; $P<0.001)$, et le temps d'insertion plus court (16 \pm 6 sec vs $30 \pm 24$ sec, respectivement; $P<0.001) . \quad$ La tension artérielle moyenne après insertion du LMA ProSeal a significativement augmenté dans le groupe témoin (62 \pm 12 à $69 \pm 17 \mathrm{mmHg} ; P=0.01$ ), mais pas dans le groupe rotation. L'incidence de taches de sang était plus basse dans le groupe rotation que dans le groupe témoin $10 \% \mathrm{vs}$ $25 \%$, respectivement; $P=0.03)$, mais aucune différence significative n'a été observée dans l'incidence de maux de gorge entre les deux groupes $(24 \%$ vs $22 \%$, respectivement; $P=0.9)$. Conclusion: La technique de rotation à $90^{\circ}$ améliore la facilité d'insertion du LMA ProSeal chez les enfants, et réduit le risque de lésions pharyngées. (Numéro de ClinicalTrials.gov, NCT01076725).

In airway management, the laryngeal mask airway $\left(\mathrm{LMA}^{\mathrm{TM}}\right)$ and the LMA ProSeal ${ }^{\mathrm{TM}}$ are useful devices that do not require a laryngoscope for insertion. They have some of the advantages of both tracheal intubation and the face mask. ${ }^{1}$ However, the insertion of the LMA or the LMA ProSeal is not always successful, and it has been reported that the larger cuff of the LMA ProSeal is more difficult to place in the patient's mouth, leaves less room for the index finger, and is more likely to fold over. ${ }^{2-4}$ The correct placement may be more difficult in children due to a relatively large tongue, a higher and more anterior larynx with a floppy epiglottis, and hypertrophied tonsils. ${ }^{5,6}$ The success rate of inserting LMAs in pediatric patients at first attempt is relatively low compared with that of adult patients (67 to $80 \%$ vs 81 to $92 \%$, respectively). ${ }^{6-8}$ Several studies ${ }^{9,10}$ were conducted to improve the insertion of these devices in pediatric patients. One technique involved insertion of the LMA with its lumen facing backwards and then rotating the device $180^{\circ}$ as it was passed downwards into position behind the larynx. This $180^{\circ}$ rotation technique was associated with a higher success rate for insertion in children than the standard technique $(99 \% \mathrm{vs}$ $79 \%$, respectively) and a lower incidence of complications, i.e., less blood on the LMA at removal ( $5 \%$ vs $17 \%$, respectively). ${ }^{6,10}$ However, the $180^{\circ}$ rotation technique was not found to offer advantages in pediatric patients over the standard insertion technique when a LMA ProSeal was applied. ${ }^{11}$ In the present study, we investigated whether the $90^{\circ}$ rotation technique was effective in pediatric patients.

\section{Methods}

The Institutional Review Board of Seoul National University Bundang Hospital approved this study, and written informed consent was obtained from the patients' parents or guardians. In total, 127 Asian children (ages 3-9, weighing 10-50 kg, and American Society of Anesthesiologists' physical status I-II) scheduled for minor eye surgery in the outpatient surgery centre were recruited. Patients were excluded from this study if they had congenital heart disease or respiratory disease that included an upper respiratory infection within the two weeks before surgery, a history of asthma, or a predicted difficult airway.

The following standardized anesthesia protocol was carried out: Intravenous access was obtained, and monitors, including an electrocardiograph, pulse oximeter, gas analyzer, and a non-invasive blood pressure device were applied before induction of anesthesia. Anesthesia was induced using thiopental sodium $5 \mathrm{mg} \cdot \mathrm{kg}^{-1}$ and maintained with $2 \%$ sevoflurane in a mixture of $50 \% \mathrm{O}_{2}$ and air. The insertion of the LMA ProSeal was attempted two minutes after an intravenous injection of alfentanil $5 \mu \mathrm{g} \cdot \mathrm{kg}^{-1}$ and rocuronium $0.6 \mathrm{mg} \cdot \mathrm{kg}^{-1}$. Heart rate and mean arterial pressure were recorded after induction and one minute before and one minute after LMA ProSeal (LMA North America, San Diego, CA, USA) insertion. During the surgical procedure, anesthesia was maintained with $1-3 \%$ sevoflurane, and no additional rocuronium was administered.

The size of the LMA ProSeal was chosen according to the manufacturer's guidelines, ${ }^{\mathrm{A}}$ i.e., size 2 for children $10-20 \mathrm{~kg}$, size 2.5 for children $20-30 \mathrm{~kg}$, and size 3 for children $30-50 \mathrm{~kg}$. A water-based gel without local anesthetic was applied to the posterior and lateral surfaces of the LMA ProSeal for lubrication, and the cuff was fully deflated before insertion. All insertions were performed in the sniffing position by two experienced individuals who had used the LMA ProSeal in more than 50 children.

The patients were assigned randomly using block randomization (four patients per block) to one of two groups, i.e., the standard technique (control group) or the $90^{\circ}$ rotation technique (rotation group).The standard technique was conducted using the index finger insertion technique according to the manufacturer's instruction manual. ${ }^{\mathrm{A}}$ Using the non-dominant hand, the patient's head was positioned with the neck flexed and the head extended. With the index finger of the dominant hand placed in the retaining strap, the LMA ProSeal was pressed against the patient's hard palate and advanced into the hypopharynx until resistance was felt. The introducer tool was not used.

\footnotetext{
${ }^{A}$ LMA Proseal ${ }^{\text {TM }}$ Instruction Manual. San Diego: LMA North America Inc; 2005.
} 
In the rotation group, the technique involved the following steps ${ }^{12}$ : Holding the mid-portion of the airway tube, the cuff of the LMA ProSeal was placed into the patient's mouth via the midline approach without finger insertion. The LMA ProSeal was rotated $90^{\circ}$ counter-clockwise from outside the patient's mouth so that the cuff was turned around the tongue and came to rest to the right side of the tongue. The LMA ProSeal was then advanced until the resistance of the hypopharynx was felt. It was then rotated back to the midline while being moved further ahead. The LMA ProSeal was connected to a breathing circuit after insertion. The cuff was inflated with air (size 2: $5 \mathrm{~mL}$; size 2.5: $7 \mathrm{~mL}$; size 3: $10 \mathrm{~mL}$ ) to $50 \%$ of the recommended maximum volume. ${ }^{13}$ The patient's lungs were ventilated using a pressure controlled mode initially set at $15 \mathrm{mmHg}$, and the respiratory rate was adjusted to achieve an endtidal $\mathrm{CO}_{2}$ pressure of $35 \mathrm{mmHg}$.

The primary outcome was ease of insertion, and it was measured by success at first attempt. Insertion time, defined as the interval between taking hold of the LMA ProSeal and achieving an effective airway, was measured by a physician blinded to the study. An effective airway was defined as normal thoracoabdominal movement and a square wave capnograph tracing during gentle manual ventilation. If insertion failed after three attempts with the same technique, one additional attempt was permitted using the other technique. The number of insertion attempts was recorded. Airway seal pressure was measured by setting the adjustable pressure limiting valve at $30 \mathrm{~cm} \mathrm{H}_{2} \mathrm{O}$, and manual ventilation was applied while listening with a stethoscope over the patient's mouth ${ }^{14}$ and epigastrium ${ }^{15}$ to detect oropharyngeal and gastric air leaks, respectively. The LMA ProSeal was repositioned if air leaked up the drainage tube or if ventilation was ineffective (expired tidal volume $<8 \mathrm{~mL} \cdot \mathrm{kg}^{-1}$ ).

The LMA ProSeal was removed after surgery when the patients were able to breathe spontaneously and open their eyes. Neostigmine $0.02 \mathrm{mg} \cdot \mathrm{kg}^{-1}$ and glycopyrrolate $0.01 \mathrm{mg} \cdot \mathrm{kg}^{-1}$ were administered to reverse the neuromuscular block. Any visible blood stain on the LMA ProSeal surface was noted at its removal, and sore throat (throat pain at rest or when swallowing) and hoarseness were assessed before the patient was discharged from the outpatient surgery centre. These evaluations were performed by another observer blinded to the method of insertion.

\section{Statistical analysis}

The primary outcome parameter of this study was the success rate of LMA ProSeal insertion at first attempt. The sample size for the study was calculated based on the results of a previous study ${ }^{10}$ with a $79 \%$ success rate of
LMA insertion at first attempt using the standard technique. Accepting a $20 \%$ improvement in success rate (i.e., $99 \%$ success with the rotational technique), 61 patients were required in each group, accepting a Type I error (two-tailed) of 0.05 and a power of 0.9. Sixty-three patients per group were enrolled to compensate for possible loss.

Results are presented as means and standard deviation or range. Insertion time was compared by the Wilcoxon ranksum test because it failed the normality test. A repeated measures analysis of variance was performed to evaluate blood pressure and heart rate. The within group differences of blood pressure and heart rate before and after insertion were analyzed with paired Student's $t$ test or the Wilcoxon signed-ranks test. Sex ratio, success rates, and the occurrence of complications were compared using Chi square analysis or Fisher's exact test. A value of $P<0.05$ was considered as indicating a statistically significant difference.

\section{Results}

Of the 127 patients enrolled, one patient in the control group was excluded when surgery was postponed due to the common cold; the remaining 126 patients completed the study. There were no differences between the two groups in terms of age, weight, height, sex, and the size of LMA ProSeal used for the surgery (Table 1). The success rate of insertion at the first attempt was greater for the rotation technique than for the standard technique (97\% vs $70 \%$, respectively; $P<0.001$ ) (Table 2). The overall success rate after three attempts was $100 \%$ for the rotational technique and $95 \%$ for the standard technique $(P=0.24)$. The LMA ProSeal was inserted in all children in the rotation group within two attempts. However, failure after three attempts occurred in three children in the control group. In these children, the LMA ProSeal was inserted at the first attempt with the rotational technique. Less time was required to achieve an effective airway with the rotational technique (16 sec vs $30 \mathrm{sec} ; P<0.001$ ) (Table 2). Airway seal pressure was similar in both groups (Table 2). The change in mean arterial pressure after insertion was greater in the control group than in the rotation group $(P=0.01)$ (Table 3$)$. The incidence of blood staining was less for the rotational technique than for the standard technique (10\% vs $25 \%$, respectively; $P=0.035$ ) (Table 3). There were two brief episodes of an abrupt increase in airway pressure (one case in each group) due to airway reflex activation during recovery from anesthesia; these resolved spontaneously without oxygen desaturation. 
Table 1 Demographic data

\begin{tabular}{lll}
\hline & $\begin{array}{l}\text { Standard group } \\
(n=63)\end{array}$ & $\begin{array}{l}\text { Rotation group } \\
(n=63)\end{array}$ \\
\hline Age $(\mathrm{yr})$ & $6 \pm 2(3$ to 9$)$ & $6 \pm 2(3$ to 9$)$ \\
Male/Female & $29 / 34$ & $32 / 31$ \\
Weight $(\mathrm{kg})$ & $26 \pm 17(10$ to 49$)$ & $24 \pm 8(13$ to 48$)$ \\
Height $(\mathrm{cm})$ & $120 \pm 14(92$ to 147$)$ & $119 \pm 14(92$ to 156$)$ \\
$\begin{array}{c}\text { Duration of } \\
\text { surgery (min) }\end{array}$ & $55 \pm 27(25$ to 130$)$ & $54 \pm 22(20$ to 105$)$ \\
\hline
\end{tabular}

Data are presented as either mean \pm standard deviation (range) or as number of patients

Table 2 Insertion results

\begin{tabular}{lll}
\hline & $\begin{array}{l}\text { Standard group } \\
(n=63)\end{array}$ & $\begin{array}{l}\text { Rotation group } \\
(n=63)\end{array}$ \\
\hline $\begin{array}{l}\text { LMA ProSeal size }(2 / 2.5 / 3) \\
\text { No. of attempts }\end{array}$ & $19 / 28 / 16$ & $18 / 34 / 11$ \\
1 & $44(70 \%)$ & $61(97 \%)^{*}$ \\
2 & $7(11 \%)$ & $2(3 \%)$ \\
3 & $9(14 \%)$ & $0(0 \%)$ \\
Fail & $3(5 \%)$ & $0(0 \%)$ \\
Insertion time $(\mathrm{sec})$ & $30 \pm 24(7$ to 112$)$ & $16 \pm 6(7 \text { to } 43)^{*}$ \\
Seal pressure $\left(\mathrm{cm} \mathrm{H}_{2} \mathrm{O}\right)$ & $24 \pm 5(14$ to 30$)$ & $24 \pm 5(12$ to 35$)$ \\
\hline
\end{tabular}

Data are numbers $(\%)$ or mean \pm standard deviation (range). LMA ProSeal $=$ ProSeal laryngeal mask airway. ${ }^{*} P<0.001 v s$ standard group

Table 3 Hemodynamic variables and complications

\begin{tabular}{|c|c|c|}
\hline & $\begin{array}{l}\text { Standard group } \\
(n=63)\end{array}$ & $\begin{array}{l}\text { Rotation group } \\
(n=63)\end{array}$ \\
\hline \multicolumn{3}{|l|}{ MAP (mmHg) } \\
\hline Before insertion & $62 \pm 12$ & $63 \pm 13$ \\
\hline After insertion & $69 \pm 17^{*}$ & $65 \pm 14 \dagger$ \\
\hline \multicolumn{3}{|l|}{ HR (beats $\cdot \min ^{-1}$ ) } \\
\hline Before insertion & $116 \pm 16$ & $113 \pm 19$ \\
\hline After insertion & $126 \pm 18^{*}$ & $121 \pm 20^{*}$ \\
\hline Blood staining on LMA ProSeal & $16(25 \%)$ & $6(10 \%) \dagger$ \\
\hline Sore throat after recovery & $14(22 \%)$ & $15(24 \%)$ \\
\hline Hoarseness after recovery & $4(6 \%)$ & $4(6 \%)$ \\
\hline
\end{tabular}

Data are mean \pm standard deviation or numbers $(\%)$. MAP $=$ mean arterial pressure; $\mathrm{HR}=$ heart rate; LMA Proseal $=$ ProSeal laryngeal mask airway. $* P<0.001$ group by insertion interaction; $\dagger P<0.05 \mathrm{vs}$ standard group

\section{Discussion}

We found that inserting the LMA ProSeal with the $90^{\circ}$ rotational technique was more successful and less traumatic in pediatric patients than the standard technique. Nakayama et al. ${ }^{10}$ reported that the $180^{\circ}$ rotational technique with a partially inflated LMA improves the ease of insertion in children. In their subsequent study, the rotational technique with a size 2 LMA ProSeal did not improve the ease of insertion in children. ${ }^{11}$ For the $180^{\circ}$ rotational technique, the mask was inserted with its lumen facing backwards, and it was then rotated $180^{\circ}$ as it passed downwards into position behind the larynx. With the $180^{\circ}$ rotational technique, there was a tendency for the mask not to rotate back completely into the correct place. ${ }^{16}$ In contrast, our study shows that the $90^{\circ}$ rotational technique is successful for inserting the LMA ProSeal in children. The $90^{\circ}$ rotation might be easier than the $180^{\circ}$ rotation, especially in children who have relatively large tongues and sometimes exhibit tonsillar hypertrophy. This may explain the greater first attempt success rate $(97 \%)$ of the $90^{\circ}$ rotational technique used in our study compared with the success rate $(85 \%)$ of the $180^{\circ}$ rotational technique used in the other study. ${ }^{11}$

The $90^{\circ}$ rotational insertion technique is straightforward; it does not require an additional device, and there is no need to insert the index finger into the oral cavity, which avoids finger trauma and glove contamination with blood or saliva. The contaminated hands of anesthesia providers can serve as a significant source of patient environmental contamination in the operating room. ${ }^{17}$ An objection to the $90^{\circ}$ rotational procedure might be that it increases the chance of injury and is more stimulating and traumatic. However, rotation of the patient's head decreases the cuff area in contact with the posterior pharyngeal wall and facilitates advancement of the LMA ProSeal into the oropharynx, especially in children with tonsillar hypertrophy. Since all subjects in this study were Asian, there might be anatomic differences between Asian and Caucasian children. Due to a small mouth cavity in two patients, we experienced slight difficulties using the rotational insertion technique with a size 2.5 LMA ProSeal. However, the LMA ProSeal was inserted successfully in these patients at the second attempt. There were no insertion failures using the $90^{\circ}$ rotational insertion technique. Moreover, the $90^{\circ}$ rotational insertion technique was successful at the first attempt, even in three patients in whom three previous attempts with the standard technique were unsuccessful. In 16 of 63 patients, more than one attempt was needed with the standard technique; it was difficult to advance the LMA ProSeal because its tip impinged on the posterior pharyngeal wall.

Thiopental and rocuronium were administered during anesthesia in this study. Although relaxation of pharyngolaryngeal muscles is not necessary for LMA ProSeal insertion, neuromuscular blocking agents are used in our institution for eye surgery. Keeping patients breathing 
spontaneously during surgery might influence the LMA ProSeal insertion success rate and postoperative pharyngeal morbidity. ${ }^{18}$

In this study, the rotational technique reduced the incidence of mucosal bleeding (10\%) compared with the index finger insertion technique (25\%), suggesting it causes less pharyngeal trauma by reducing resistance to LMA ProSeal tip advancement past the posterior pharyngeal wall. The incidence of sore throat was not significantly different between the two groups in our study. More children reported sore throat in the rotation group than in our previous report for adults (24\% vs $8 \%$, respectively). ${ }^{19} \mathrm{It}$ might be difficult for young children to give correct information and differentiate pain from fear. We did not follow up the incidence of sore throat after discharge from the outpatient surgery centre.

This study has several limitations. It was impossible to blind the anesthesiologists to the insertion technique, a possible source of bias, even though assessment of variables was conducted by another person blinded to the insertion method. We did not evaluate the position of the LMA ProSeal with a fibrescope, although this approach is recognized as the standard method to assess placement. Judging the correct placement on clinical grounds may be considered normal in clinical practice. ${ }^{20}$ The insertion technique was not evaluated in children under the age of three years because of their difficulty in reporting symptoms of sore throat.

In conclusion, the $90^{\circ}$ rotational insertion technique improves ease of inserting the LMA ProSeal and results in less pharyngeal trauma in pediatric patients.

Conflicts of interest None declared.

Funding Institutional and departmental resources only.

\section{References}

1. Joshi S, Sciacca RR, Solanki DR, Young WL, Mathru MM. A prospective evaluation of clinical tests for placement of laryngeal mask airways. Anesthesiology 1998; 89: 1141-6.

2. Brimacombe $J$, Keller $C$. The ProSeal laryngeal mask airway: a randomized, crossover study with the standard laryngeal mask airway in paralyzed, anesthetized patients. Anesthesiology 2000; 93: 104-9.

3. Cook TM, Nolan JP, Verghese C, et al. Randomized crossover comparison of the proseal with the classic laryngeal mask airway in unparalysed anaesthetized patients. Br J Anaesth 2002; 88: 527-33.

4. Brimacombe J, Keller C, Fullekrug B, et al. A multicenter study comparing the ProSeal and Classic laryngeal mask airway in anesthetized, nonparalyzed patients. Anesthesiology 2002; 96: 289-95.

5. Pennant JH, White PF. The laryngeal mask airway. Its uses in anesthesiology. Anesthesiology 1993; 79: 144-63.

6. Ghai B, Makkar JK, Bhardwaj N, Wig J. Laryngeal mask airway insertion in children: comparison between rotational, lateral and standard technique. Paediatr Anaesth 2008; 18: 308-12.

7. Cook TM, Lee G, Nolan JP. The ProSeal laryngeal mask airway: a review of the literature. Can J Anesth 2005; 52: 739-60.

8. Johnston DF, Wrigley SR, Robb PJ, Jones HE. The laryngeal mask airway in paediatric anaesthesia. Anaesthesia 1990; 45: 924-7.

9. Kundra P, Deepak R, Ravishankar M. Laryngeal mask insertion in children: a rational approach. Paediatr Anaesth 2003; 13: 685-90.

10. Nakayama S, Osaka Y, Yamashita M. The rotational technique with a partially inflated laryngeal mask airway improves the ease of insertion in children. Paediatr Anaesth 2002; 12: 416-9.

11. Watanabe K, Nakayama S, Yamashita M. The rotational technique with ProSeal laryngeal mask airway does not improve the ease of insertion in children. Paediatr Anaesth 2006; 16: 598-9.

12. Jeon YT, Na HS, Park SH, et al. Insertion of the ProSeal laryngeal mask airway is more successful with the 90 degrees rotation technique. Can J Anesth 2010; 57: 211-5.

13. Brimacombe J, Holyoake L, Keller C, et al. Pharyngolaryngeal, neck, and jaw discomfort after anesthesia with the face mask and laryngeal mask airway at high and low cuff volumes in males and females. Anesthesiology 2000; 93: 26-31.

14. Lopez-Gil M, Brimacombe J, Keller C. A comparison of four methods for assessing oropharyngeal leak pressure with the laryngeal mask airway (LMA) in paediatric patients. Paediatr Anaesth 2001; 11: 319-21.

15. Brimacomb J, Keller C, Kurian S, Myles J. Reliability of epigastric auscultation to detect gastric insufflation. $\mathrm{Br} \mathrm{J}$ Anaesth 2002; 88: 127-9.

16. Brimacombe J, Berry A. Insertion of the laryngeal mask airwaya prospective study of four techniques. Anaesth Intensive Care 1993; 21: 89-92.

17. Loftus RW, Muffly MK, Brown JR, et al. Hand contamination of anesthesia providers is an important risk factor for intraoperative bacterial transmission. Anesth Analg 2010; DOI: 10.1213/ANE. 0b013e3181e7ce18.

18. Figueredo E, Vivar-Diago M, Munoz-Blanco F. Laryngo-pharyngeal complaints after use of the laryngeal mask airway. Can J Anesth 1999; 46: 220-5.

19. Hwang JW, Park HP, Lim YJ, Do SH, Lee SC, Jeon YT. Comparison of two insertion techniques of ProSeal laryngeal mask airway: standard versus 90-degree rotation. Anesthesiology 2009; 110: 905-7.

20. Matta BF, Marsh DS, Nevin M. Laryngeal mask airway: a more successful method of insertion. J Clin Anesth 1995; 7: 132-5. 